\section{Review of Loropetalum chinense as an Industrial, Aesthetic, and Genetic Resource in China}

\author{
Wei Wu
}

The Institute for Sustainable Development, Macau University of Science and Technology, Macau 9990798, China; and Jiangxi Key Laboratory of Plant Resources and Biodiversity, Jingdezhen University, Jingdezhen 333400, China

\author{
Shijia Wen \\ College of Forestry, Hainan University, Haikou 570228, China; and \\ Jiangxi Key Laboratory of Plant Resources and Biodiversity, Jingdezhen \\ University, Jingdezhen 333400, China

\section{Tangkai Feng} \\ Jiangxi Key Laboratory of Plant Resources and Biodiversity, Jingdezhen \\ University, Jingdezhen 333400, China
}

\section{Guoke Chen}

State Key Laboratory of Vegetation and Environmental Change, Institute of Botany, the Chinese Academy of Sciences, Beijing 100093, China

\section{Bo Yang \\ Jiangxi Key Laboratory of Plant Resources and Biodiversity, Jingdezhen University, Jingdezhen 333400, China}

Additional index words. ornamental plant, germplasm resource, research and utilization, resource economy

\begin{abstract}
Loropetalum chinense, one of three species in its genus in China, is distributed primarily in Hunan and Jiangxi Provinces. By establishing a Loropetalum gene bank and reviewing research on its varieties, genetic traits, and genetic diversity, we hope to promote the full yet sustainable use of this valuable, regionally varied natural resource. Our results will help promote the development of a broader resource economy.
\end{abstract}

Loropetalum chinense (R. Br.) Oliv., commonly known as bafajimu, zhimu, or zhimofa, is a hardwood species often used as firewood in the mountainous regions of southern China. Its flexible branches can be used for bundling firewood or as cordage for assembling wooden rafts. When flowering, individual flowers are clustered and can cover entire branches, blooming like fireworks in the green mountains. $L$. chinense can regenerate after damage to $90 \%$ of its main stem, which illustrates the vigorous metabolic capacity of the plant's callus cells. In Origin of Chinese Characters of

Received for publication 21 May 2021. Accepted for publication 15 July 2021.

Published online 7 September 2021.

This work was funded by the National Natural Science Foundation of China (32060309, 41561014) and the Science and Technology Projects of Jiangxi Provincial Department of Education (GJJ191163, GJJ191177).

We are grateful to Ding Wu and Qiao-jun Jin for suggestions regarding the article's arrangement of ideas and materials.

B.Y. is the corresponding author. E-mail: yangbomvp@aliyun.com.

This is an open access article distributed under the CC BY-NC-ND license (https://creativecommons. org/licenses/by-nc-nd/4.0/).
L. subcordatum (Benth.) Oliver. Loropetalum chinense is widely distributed in China, Japan, and northeastern India; the other two species are endemic to China. The word Loropetalum derives from the Latin description of the flower type. Each flower has four to six banded petals, and several flowers grow together in clusters. Although the classification of Loropetalum has been reviewed previously, its cultivation, promotion, and use as ornamental plants has only occurred during the past 30 years. The main biological characteristics and uses of each species are summarized in Table 1.

L. chinense is a shrub or small tree with leathery, ovoid leaves characterized by a slight fuzziness on the top and star hairs on the bottom; membranous and caducous stipules; clusters of three to eight bisexual flowers; and four tongue-like petals per flower. Flowers often open before leaves appear. It is distributed in the southern regions of China, especially the high mountains. Loropetalum spp. have strong prospects for increased production because of their number of applications. L. chinense is a common species in subtropical, evergreen, broad-leaved forests and is encountered mostly on hillsides or under sparse canopies. It is widely distributed in central and southern China (Fig. 1), and is also found occasionally in Japan and northeast India.

L. chinense var. rubrum was discovered and named in Changsha's Tianxin Garden in 1938 by the famous forest scientist Peizhong Ye (Hou et al., 2005). The leaf shape is the same as the parent species. It is a rare ornamental variety native to Liuyang, Hunan (Huang et al., 1998). The flowers and leaves are both red, four to eight flowers are arranged in short spikes, and the petals are ribbon-like. The color of the flowers varies from pink to purple, and flowers can bloom multiple times a year, aperiodically. As a result, $L$. chinense var. rubrum is widely used as ornamental plants for viewing flowers and leaves south of the Yangtze River. The variety can be found growing naturally scattered in the low-elevation areas of Mt. Luoxiao at the border of Hunan and Jiangxi Provinces. Collecting wild seeds of $L$. chinense var. rubrum for training and cultivation offers an opportunity to enrich and improve garden groundcover and ornamental displays, with implications for landscape ecology on a wider scale.

\section{Development and Use of Germplasm Resources}

Large-scale production and use of L. chinense var. rubrum has led to genetic intermixing between varieties and confusion in optimal cultivation techniques. The purpose of this review is to collate diverse literature and other information sources to establish what is known about the cultivation, use, and research needs concerning $L$. chinense. In doing so, we hope to facilitate future research and promote sustainable, effective use of this precious ornamental plant

Genetic research. L. chinense var. rubrum was first discovered in Dawei Mountain in the 1980s. At one point it drove the development of the local economy through 
Table 1. Species, biological characteristics, resource evaluation of the genus Loropetalum in China.

\begin{tabular}{|c|c|c|}
\hline Name & Biological characteristics & Resource evaluation \\
\hline$\overline{\text { Loropetalum lanceum }}$ & $\begin{array}{l}\text { Evergreen tree; young branches with slender twigs; thin, leathery } \\
\text { leaves; lanceolate or ovate-lanceolate, with four to five flowers } \\
\text { clustered into short spikes with white ribbon petals }\end{array}$ & $\begin{array}{l}\text { Distributed only in south Guangxi. Flowers } \\
\text { and leaves have ornamental value. }\end{array}$ \\
\hline Loropetalum chinense & $\begin{array}{l}\text { Shrubs or small trees; leathery, oval leaves; three to eight flowers } \\
\text { in clusters; four tongue-like petals, often opening before new } \\
\text { leaves; round, ovoid seeds }\end{array}$ & $\begin{array}{l}\text { Distributed in the middle and lower reaches of } \\
\text { the Yangtze River, and in the regions to the } \\
\text { south. Often used as hedges or bonsai. }\end{array}$ \\
\hline
\end{tabular}

active introduction, propagation, and cultivation activities. As a result, Hunan Liuyang became the "hometown of Loropetalum chinense var. rubrum." Because of the obvious geographic distribution pattern of its genetic resources, it was recognized as China's geographic symbolic product (Shao et al., 2007). As a brightly colored tree suitable for landscaping, $L$. chinense var. rubrum has been sold to nearly 20 provinces and municipalities, including Jiangsu, Zhejiang, and Hubei, and became the flower symbol of Changsha and Zhuzhou in Hunan Province.

The floral structure of Loropetalum, including petals, stamens, staminodes, and sepals, is a four-digit flower, which is an important feature in differentiating it from other genera in Hamamelidaceae. The difference between $L$. chinense and $L$. chinense var. rubrum not only includes variations in leaf and flower color (Fig. 2), but also the genetic number of flower structures. The results showed that four-digit flowers account for $92.6 \%$ of wild $L$. chinense (Xu and Zhang, 2003). Further research by Wang (2007) showed that in wild $L$. chinense var. rubrum, four-digit flowers account for $50.0 \%$ to $51.9 \%$; five-digit flowers, $44.9 \%$ to $45.9 \%$; and six-digit flowers, $3.2 \%$ to $4.8 \%$.

$L$. chinense var. rubrum is a mutant of $L$. chinense that is characterized by a much greater anthocyanin content in its leaves. As a result, they appear reddish brown, purplish brown, and purplish black. $L$. chinense var. rubrum can be divided into three categories by leaf color: young red, penetrating red, and double red. The flowers of the cultivated types of $L$. chinense var. rubrum were five digit, accounting for $53.3 \%$ (Wang, 2007). The overall distribution pattern of flower digital structure has four digits is the most common (and thus five- and six-digit flowers are the least common) in young red, followed by penetrating red and then double red. It can be inferred that the uneven distribution of flower digital structure reflects the influence of human cultivation, which accelerates the variation of genetic diversity (Hou et al., 2003).

L. chinense var. rubrum does not breed true. Leaf color in seedlings is often unstable, and $15.8 \%$ of seedlings have green leaves (Song and Tan, 1981). When new leaves first appear in spring, the flowers and leaves of $L$. chinense var. rubrum are red. The leaf color changes with leaf age, slowly changing to dark red in early summer, and "high-temperature green" in midsummer (Tang et al., 2006). Genetic instability greatly reduces the ornamental value of $L$. chinense var. rubrum. Studying the mechanism of leaf color change and ways to prevent red leaves from turning green have great theoretical and practical significance for improving ornamental value and

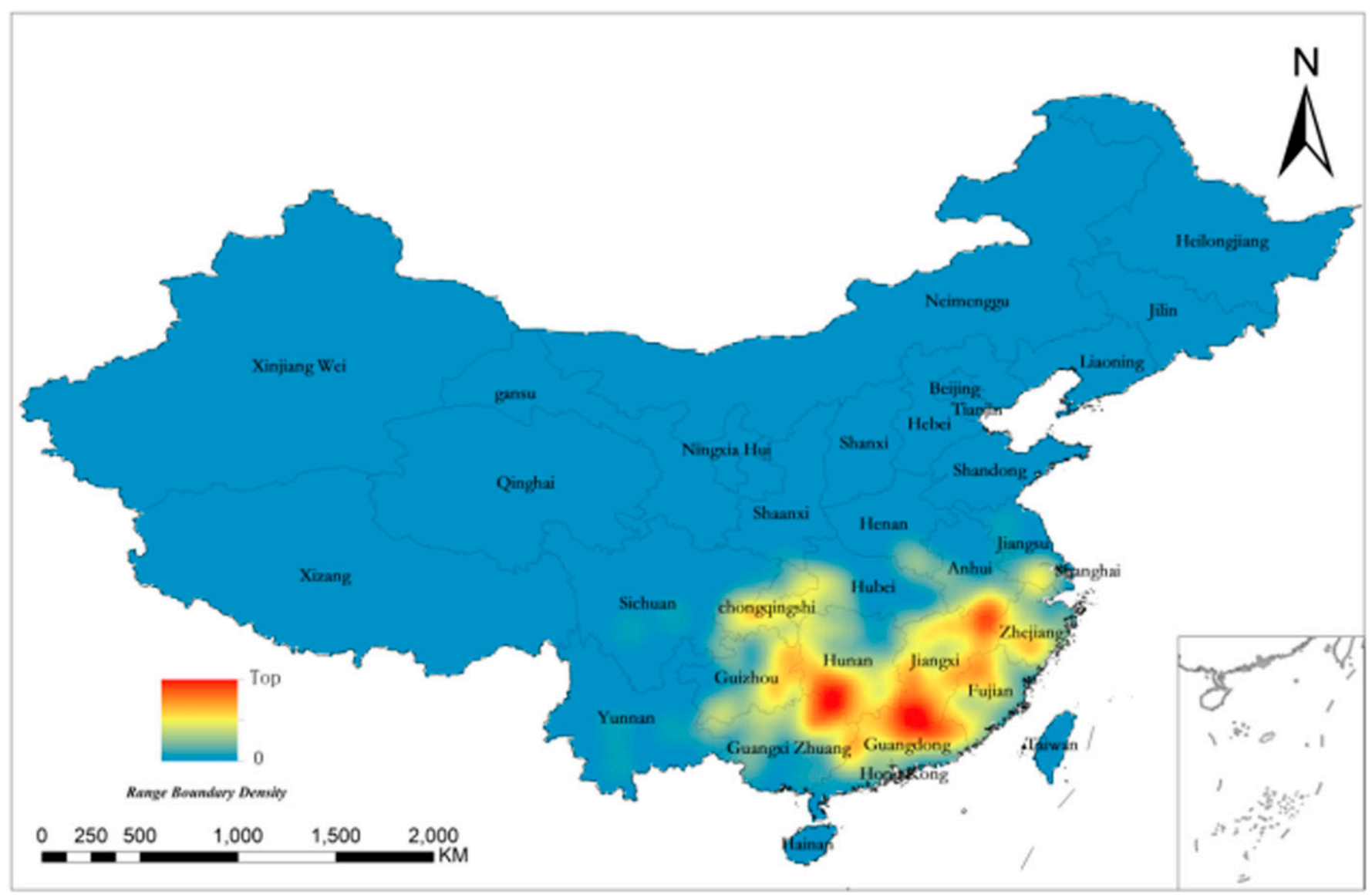

Fig. 1. Geographic distribution of Loropetalum chinense in China. In the range density map, the redder the color, the more common $L$. chinense. Data from the National Plant Specimen Resource Center. 

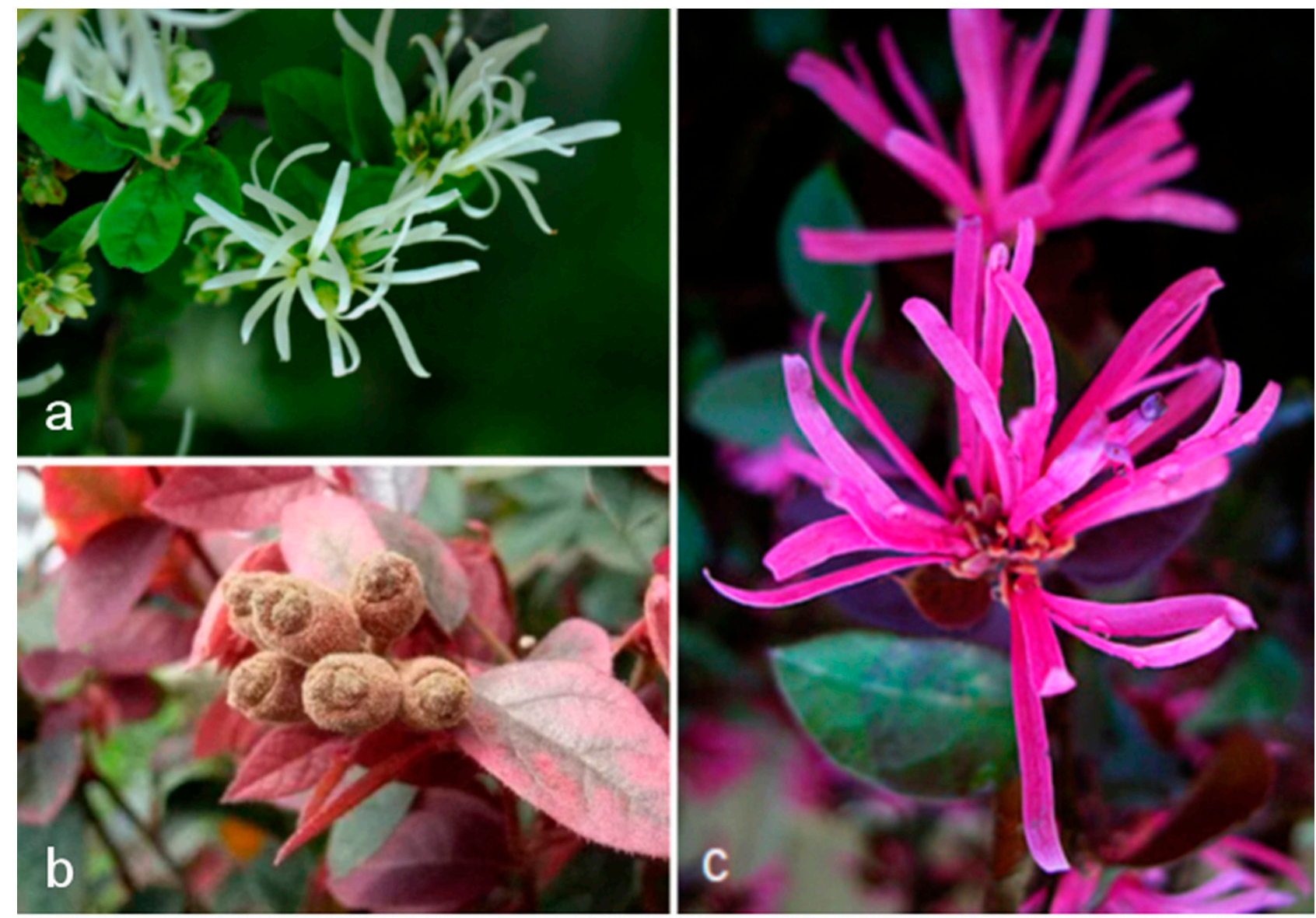

Fig. 2. Flower morphology of Loropetalum chinense and L. chinense var. rubrum. (A) Flowers of L. chinense. (B) Fruit of L. chinense var. rubrum.

(C) Flowers of L. chinense var. rubrum. (Photographs from Plant Photo Bank of China.)

breeding new varieties of $L$. chinense var. rubrum (Jiang et al., 2005; Yuan et al., 2010).

The development of modern molecular biology has provided technical support for the continuous development and use of genetic resources. The ornamental value of $L$. chinense var. rubrum is related closely to the content of anthocyanin in the leaves, which is affected by light, temperature, soil $\mathrm{pH}$, and other factors. For example, light promotes the production of anthocyanins, and shading or removing leaves severely inhibits the synthesis of anthocyanins (Kawabata et al., 1995). High temperatures decreased the content of anthocyanin in leaves of $L$. chinense var. rubrum. The synergistic stress conditions of high temperatures and strong light or high temperatures and humidity accelerate the degradation of anthocyanins, whereas mild drought favorites the stability of anthocyanins (Huang et al., 2017).

Medicinal value. L. chinense var. rubrum is an important ornamental plant, and is widely used and studied in horticulture. However, studies about L. chinense are rare, despite its importance in folk medicine. According to the Record of Plant Names (Zhang, 2006), L. chinense has the effects of "healing and stopping bleeding, astringent intestines and diarrhea, muscle growth, and analgesic," and is often used to treat traumatic bleeding. Flavonoids in Loropetalum have antibacterial, anti-inflammatory, sedating, and other functions, and also have significant effects in terms of antioxidation and anticancer. $\mathrm{Xu}$ et al. (1996) pointed out that total flavonoids, tannins, fatty acids, phenolic substances, and organic acids contain effective ingredients of medicinal value.

Studies have shown that there are many types of flavonoids in Loropetalum, of which the main three types are quercetin, kaempferol, and myricetin. Quercetin inhibits the effect of cancer-promoting agents significantly, kaempferol reverses the multidrug resistance of tumor cells, and myricetin has a hypoglycemic effect, platelet activating factor antagonism, an antioxidant effect, and so on. The properties of these three types of flavonoids may underpin the medicinal value of Loropetalum species (Tian, 2010). L. chinense contains tannins, flavonoids, and polyphenols that may be the basis of its medicinal value (Feng, 2013).

Lian et al. (2013) studied the crude extract of $L$. chinense, which can speed wound healing in rats significantly (i.e., shorten skin healing time), increase the tensile strength of the skin, and promote the regeneration of cell and blood vessels in the wound. Liu et al. (2008) extracted flavonoid from $L$. chinense, and obtained a Chinese National Patent (CN101153303A). In 2009, Jiangxi Deyu Group Co. Ltd. received funding for the project "The research and development and demonstration of the key technology for extracting medicinal components of $L$. chinense" from the Ministry of Science and Technology, aiming to solve the key problems of L. chinense reproductive success, transplantation, and the extraction of bioactive substances. These studies have laid a foundation for further study and use of Loropetalum flavonoids.

L. chinense var. rubrum is rich in tannins, with a variety of biological properties. Zhou et al. (2007) provided evidence that the antibacterial components in its leaves are coumarins and tannins, but the exact monomer remains to be identified. This species is also used in the extraction of natural food colorants. Its anthocyanin has strong antibacterial properties and can be used as a constituent of antimicrobial and anti-inflammatory drugs. It can also be used as an antimicrobial food preservative and color enhancer, as well as an additive for other products ( $\mathrm{Li}$ et al., 2008). The development and use of $L$. chinense var. rubrum, and the extraction of natural food pigments are thus also of great significance for protecting the health of consumers and promoting the development of the food industry.

\section{Industrial Applications}

Genetic resources are important strategic resources for the national interest, security, and sustainable economic and social development of a country. A species can influence 
the economic lifeline of a region, which has been proved by many biological and foodsecurity incidents in history. For example, New Zealand has developed a huge industry that now dominates the international kiwifruit (Actinidia chinense Planch. native to China) market (Huang, 2009).

Resource economics. According to the Convention on Biological Diversity, genetic resources are genetic material in a species with practical or potential value (Mao and $\mathrm{Fu}, 2011)$. Resource economics is a special science based on economic theory, which studies the rational allocation of resources, the coordination with population and environment, and the sustainable development of resource economy by means of economic analysis. Before the $1980 \mathrm{~s}$, the focus of resource economics and research was to solve problems related to resource shortages or crises. With the rapid economic development and the impact of global climate change, we have been losing plant genetic resources at an alarming rate. Plant genetic resources have driven the transformation of traditional to modern agriculture.

Breeding programs are the primary means of capitalizing on plant genetic resources through the creation of desirable cultivars and seed banks. L. chinense was introduced to North America in the early 20th century as an ornamental plant (Dirr et al., 1995; Freek, 1994), and it is widely cultivated in the United States now. It was not until its introduction in the 1980 s that $L$. chinense var. rubrum caught the attention of the American horticultural community (Michael, 1998). Loropetalum seedlings and bonsai plants have been sold in large quantities throughout China, and have been exported to Japan, South Korea, Singapore, Britain, Switzerland, and other countries, becoming a staple of China's flower industry (Hou et al., 2005).

Among the commonly colored plants such as Acer rubrum, Acer pictum subsp. mono, Prunus salicina, Photinia fraseri, $L$. chinense var. rubrum, and so on, only the flowers and leaves of $L$. chinense var. rubrum match in color. The species is an extremely precious ornamental plant, with a long flowering period and beautiful posture in modern urban gardens. With the continuous improvement of living standards in recent years, people have increasing requirements for the quality and aesthetics of garden settings, and garden and road-greening plants.

At the same time, the development and use of special genetic resources have broader market prospects and development potential. Nowadays, the garden industry is forming regional conglomerates and becoming an important pillar industry in some regions (Zhang and Pan, 2001). Examples include Kunming's fresh-cut flowers in Yunnan, Jinhua's Camellia japonica and Citrus chirocarpus in Zhejiang, Dayu's Daphne odora and Ardisia japonica in Jiangxi, Nanzhao's Magnolia denudata in Henan, Junling's Prunus mume in Henan, and so on.

In the context of international trade and economic and technical cooperation, the development and use of genetic resources also have an important impact on global industry and economic development. For example, Israel, originally a country with extremely poor flower resources, has become a large producer of flowers and plants thanks to the sharing of genetic resources. More than $80 \%$ of seedlings of ornamental plants grown for their flowers are imported; no genetic resource nursery has been established to collect introduced varieties. There is a need for additional varieties that have not been patented (Zhou et al., 2011). L. chinense var. rubrum has Mosaic disease, which affects green landscapes. It is necessary to strengthen the construction of nontoxic seedlings breeding systems, and build the mother garden based on nontoxic seedlings for cutting and grafting (Wang, 2007).

Construction of a gene bank. Carrying out wild genetic resources surveys and establishing a gene bank will not only preserve germplasm resources, but also will gradually expand seedling reproduction, transform wild resources into cultivated species, and enrich the diversity of garden plants (Liu and Zhang, 2001). It has been noted that breeding and cultivation are best carried out by selecting mother trees with better flowers and leaves. Using $L$. chinense as a rootstock and grafting the stems of $L$. chinense var. rubrum has led to successful cultivation of bonsai or tree bonsai (Cao, 1983). There are many benefits to constructing a large-scale gene bank for $L$. chinense. Such a facility could aid in the genetic and systematic research on the species, safeguard regional diversity, and provide new and better stock for industry.

Wild $L$. chinense var. rubrum has nearly disappeared, so it is urgent to collect genetic resources extensively, including optimal provenances, families, and varieties. There has been some success in breeding varieties with different shapes and colors of flowers and leaves. However, most breeding is done by simply crossing vegetative lines. The speed of genetic improvement and innovation is relatively slow, and many existing varieties are relatively scarce. The leaf color of most existing commercial stock is purplish red, which does not meet the market demand. Therefore, it is important to carry out research on genetic improvement of the leaf color of $L$. chinense var. rubrum and explore the underlying mechanism driving leaf color change (Shao et al., 2007).

During the processes of introduction and cultivation, we found there were many new varieties and excellent strains of $L$. chinense. However, a lack of classification and breeding often resulted in a low commodity value of the varieties. In addition, as a result of intensification and monoculture practices, some types of $L$. chinense var. rubrum with high potential have been neglected or cannot be used scientifically, and thus are in danger of extinction. Therefore, it is crucial to establish a genetic resource bank and breeding programs, develop new varieties, and expand the cultivation of $L$. chinense var. rubrum

$L$. chinense can be used for grafting and breeding of $L$. chinense var. rubrum.
Therefore, it has high economic value and development potential (Liu et al., 2012). With environmental changes, logging, and slow natural regeneration rates, wild Loropetalum is declining. To protect and maximize the benefits of this resource, Jingdezhen Deyu Ecological Garden has collected 50,000 strains of ancient Loropetalum, and now more than 500,000 Loropetalum plants have been established. The special Loropetalum garden covers an area of 40 ha and has become a unique asset for Chinese herbal medicine.

Landscaping applications. Because of its strong adaptability, L. chinense var. rubrum can grow very well with dry, barren, acidic, and calcareous soils (Zhou et al., 2011). In the middle and lower reaches of the Yangtze River, it generally flowers each season of the year, but blooms mainly in spring. Because flowers can be seen throughout the four seasons, L. chinense var. rubrum is one of the most well-known, and is a great example of successful domestication and commercial cultivation from the wild in the 20th century (i.e., the integration of wild plant species into human-dominated landscapes) (Tang and Peng, 2009).

Urban greening has begun to embrace three dimensions and bright colors, and as a result colorful plants are favored increasingly by the greening community. Various forms of $L$. chinense var. rubrum can be observed in the green spaces in Nanjing, Nanchang, and Jiujiang, and more than $85 \%$ of planners have chosen to incorporate it into managed landscapes (Zhou et al., 2011). L. chinense var. rubrum is applied in street greening and hedgerow cultivation, can also be used with other plants, and can be trimmed into spherical and animal shapes. Arboretums of L. chinense exclusively have been established (Fig. 3). During the spring and summer seasons, the Jingdezhen Deyu Ecological Park in Jiangxi is decorated with red and white flowers - notably, the trees grafted with the ancient Loropetalum stems. The first China Jingdezhen Loropetalum festival was held successfully in 2011 .

The ornamental and ecological value of Loropetalum should be emphasized. L. chinense var. rubrum has been introduced into cities to improve species richness and genetic diversity of urban green spaces. One main task of resource economics is to transform resource advantages into industrial advantages. Plant genetic resources are special kind of renewable materials and strategic resources, which also refer with potential practical value. Magnolia biondii Pamp., also known as Yulan, originated in Nanzhao, Henan Province. Nanzhao wins the title of China Yulan Township, with the largest Yulan horticulture industry and the largest Yulan park in China (Bi et al., 2020). It is famous as a tourist hotspot and a place of research.

After years of introduction and domestication, the species can be grown in central, southern, and southwestern China. Currently present, challenges persist in L. chinense nomenclature - in particular, because the names of its variants are mixed with commodity names. Many types and varieties have 

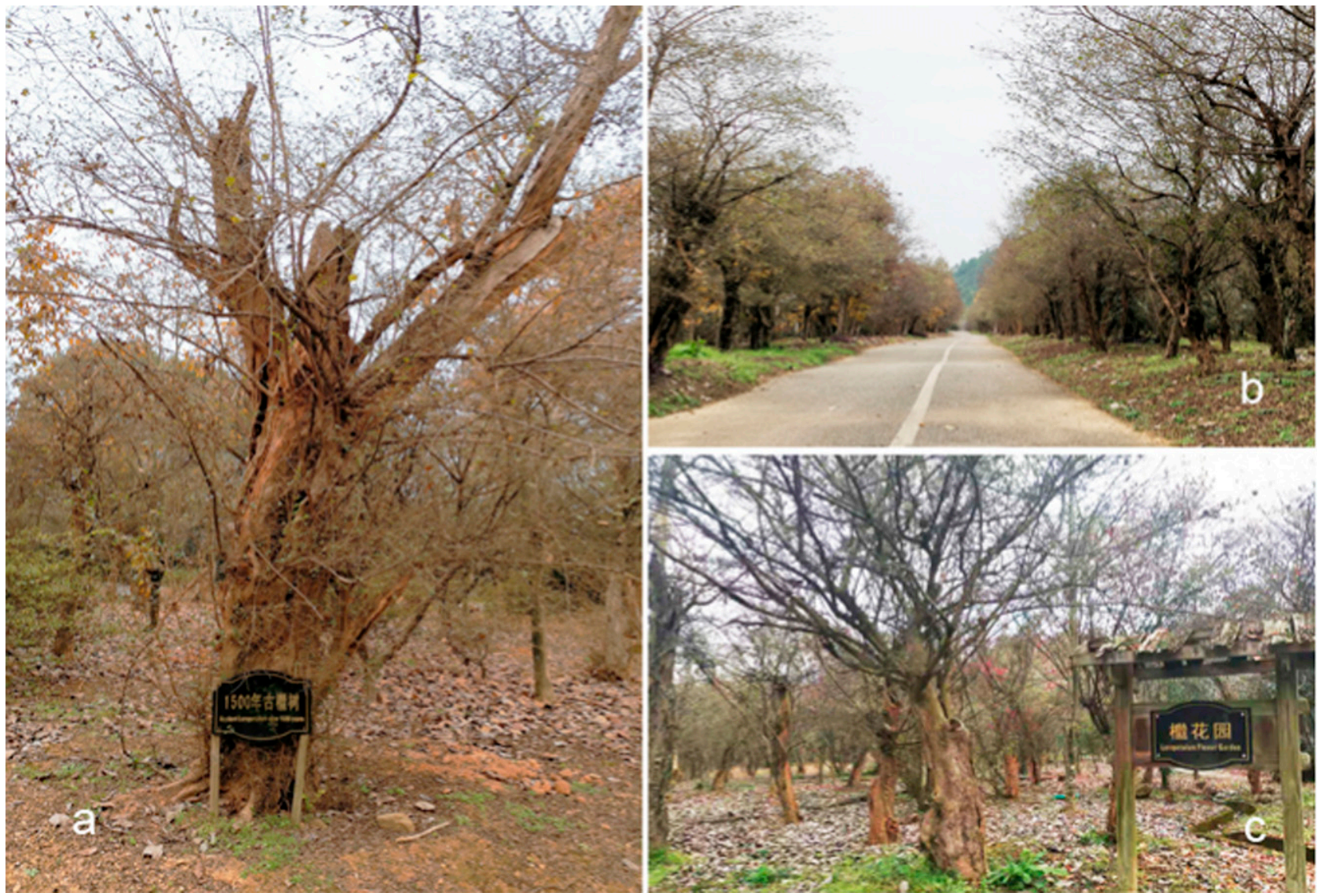

Fig. 3. Deyi Ecological Garden of Jingdezhen, Jiangxi. (A) An ancient Loropetalum over 1500 years old. (B) A Loropetalum shade tree. (C) A Loropetalum flower garden. (Photographs by Ding Wu.)

not been named, which can forestall further development and use. Additional research identification and genetic comparison of $L$. chinense variants is needed to facilitate their universal diffusion and cultivation.

\section{Literature Cited}

Bi, X.W., Y.Q. Shen, J.H. Yang, Y.Q. Chai, and X.H. Cheng. 2020. Situation of forestry germplasm resources and construction of genetic bank in Nanyang, Henan Province. J. Henan For. Sci. Technol. 40(1):35-37.

Brown, R. 1818. Loropetalum. In: Z.Y. Wu and P.H. Raven (eds.). 2003, Flora of China. Science Press, Beijing, 9:32-34.

Cao, Z.Q. 1983. Brief introduction of peeling and fitting Loropetalum chinense var. rubrum. Hunan Garden 1:12-13.

Dirr, M.A., Y.Q. Huo, and S.A. Hartxler. 1995. Asynopsis of pink flowed Loropetalum, Loropetalum chinense var. rubrum. Nursery Mgt. Production 11:30-31.

Feng, T.K. 2013. Research progress of the flavonoid and its metabolic pathways in white flowers Loropetalum chinense. Anhui Agr. Sci. Bull. 19(19):29-30.

Freek, V. 1994. International registration of cultivar Nanes for unassigned woody genera. HortScience 29:970-971.

Hou, B.X., Z.H. Cheng, F. Lin, G.F. Yu, and A.Q. Yi. 2005. Ancient trees resources and conservation status. Hunan For. Sci. Technol. 30(3): $47-48$.

Hou, B.X., F. Lin, G.F. Yu, and A.Q. Yi. 2003. Study of the number variation of outward characteristic of the Loropetalum chinense var. rubrum. J. Plant Genet. Resources 4(3):203-206.

Huang, H.W. 2009. History of 100 years of domestication and improvement of kiwifruit and gene discovery from genetic introgressed populations in the wild. Chinese Bul. Bot. 44(2):127-142.

Huang, R.K., J.G. Yang, Z.H. He, J.C. Li, and Y.Q. Liu. 1998. Investigation and research on Loropetalum chinense var. rubrum. Hunan Agr. Sci. 4:44-45.

Huang, X., H.X. Wang, K.D. Sun, M. Lin, J.H. Li, and L.N. Sun. 2017. Changes of pigment content and net photosynthetic rate of Loropetalum chinense var. rubrum leaves in hot season. Hunan Agr. Sci. 4:43-45.

Jiang, W.B., M. Zhuang, and G.P. Hua. 2005. Research progress on the coloring mechanism and photosynthetic characteristics of colorfulleaf plants. Acta Hort. Sinica 32(2):352-358.

Kawabata, S., M. Ohta, Y. Kusuhara, and R. Sakiyama. 1995. Influences of low light intensities on the pigmentation of Eustoma grandiflorum flowers. Acta Hort. 405:173-178.

Li, D., X.Y. Yu, X.Y. Xiong, L.Y. Wu, J. Yao, S. Qiu, and X. Xiong. 2008. Researches and utilization of Loropetalum chinense var. rubrum germplasm resources. Nonwood Forest Res. 26(1): $117-121$.

Lian, Z.Q., J. Gao, X.B. Li, H.Y. Liu, and H.B. Zhu. 2013. Preliminary study on the material basis of Loropetalum chinense in promoting skin wound healing in rats. China J. Chinese Materia Medica 38(2):3566-3570.

Liu, H.Y., X.B. Li, and Z.R. Zhan. 2008. A preparation method of flavonoids from Loropetalum chinense. Chinese National Patent, CN1011 53303A.
Liu, H.Y., X.B. Li, Z.R. Zhan, G.B. Jiang, M. Zhang, J. Wan, A.Z. Zhou, X.Z. Xia, and L. Zhang. 2012. Thinking of germplasm resources protection and use of Loropetalum chinense. Jiangxi Forest Sci. 6:46-47.

Mao, Y. and G.H. Fu. 2011. Research on the development of germplasm resources economics. Ecol. Econ. 7:43-46.

Michael, A.D. 1998. Manual of woody landscape plants. Stipes Publishing LLG, Champaign, IL.

Mione, T. and A.L. Bogle. 1990. Comparative ontogeny of the inflorescence and flower of Hamamelis virgineana and Loropetalum chinense. Amer. J. Bot. 77(1):77-91.

Oliver, D. 1862. Loropetalum chinense In: Z.Y. $\mathrm{Wu}$ and P.H. Raven (eds.). 2003, Flora of China. Science Press, Beijing, 9:33.

Shao, Z.X., W. Hou, X.Z. Long, G.D. Yang, C.H. Chen, X.J. Zeng, B.X. Hou, G.F. Yu, and F.F. $\mathrm{Wu}$. 2007. The formation and development of the geography symbol product Loropetalum chinense var. rubrum in Liuyang city. Hunan Forest Sci. 34(2):71-73.

Song, J.Y. and Z.X. Tan. 1981. The biological characteristics and cultivation of Loropetalum chinense var. rubrum. Hunan Garden 2:29-31.

Tang, Q.R., D.F. Chen, and Y.Y. Chen. 2006. Physiological and biochemical study on leaf color changes of Loropetalum chinense var. rubrum. For. Sci. 42(2):111-115.

Tang, X.H. and S.H. Peng. 2009. China's Loropetalum chinense var. rubrum industry development status and suggestions. Hunan For. Sci. Technol. 36(5):37-39.

Tian, H. 2010. Study on the total flavonoids in the chemical constituents of Loropetalum chinense leaves. Gems Health 3:78-79. 
Wang, Y. 2007. The research process of germplasm resource and inherited character of Loropetalum chinense var. rubrum. J. Hunan Univ. Arts Sci. 19(1):66-71.

Wu, Z.Y. and P.H. Raven (eds.). 2003. Flora of China. Science Press, Beijing 9:32-34.

$\mathrm{Xu}$, S. 2003. Origin of Chinese Characters. Zhonghua Book Company, Shanghai, 3507 .

$\mathrm{Xu}$, G.F. and C.Y. Zhang. 2003. Study on the floral structure and pollen vitality of Loropetalum chinense var. rubrum. J. Jilin Agr. Univ. 25(5):520-522.
$\mathrm{Xu}$, G.J., H.X. He, L.S. Xu, and R.L. Jin 1996. Chinese medicinal materials: Volume 2. China Medical Science Press, Beijing, China.

Yuan, M., X.J. Jia, and Z.H. Duan. 2010. Leaf morphological characteristics and pigment content changes during the leaf color change of Loropetalum chinense var. rubrum. J. Sichuan Agr. Univ. 28(1):73-77.

Zhang, H.F. 2006. The evolution of biosynthetic pathways of flavonoids and its research prospects in Epimedium. Chin. Traditional Herbal Drugs 11:1745-1751.
Zhang, Q. and H.T. Pan. 2001. Current status and countermeasures of introducing foreign ornamental plants in China, p. 133-142. In: Advances in science and technology of flowers and plants in China. China Agriculture Press, Beijing.

Zhou, D.D., W.B. Jiang, J.X. Wei, and M.L. Weng. 2011. Cultural connotations of Loropetalum chinense var. rubrum and its application in landscaping. Acta Agr. Jingxi 23(8):24-26.

Zhou, G.H., H.Z. Yu, C. Lu, and Z. Zhou. 2007. Primary study on bacteriostatic active compound from leaves of Loropetalum chinense var. rubrum. Food Sci. 28(6):74-77. 